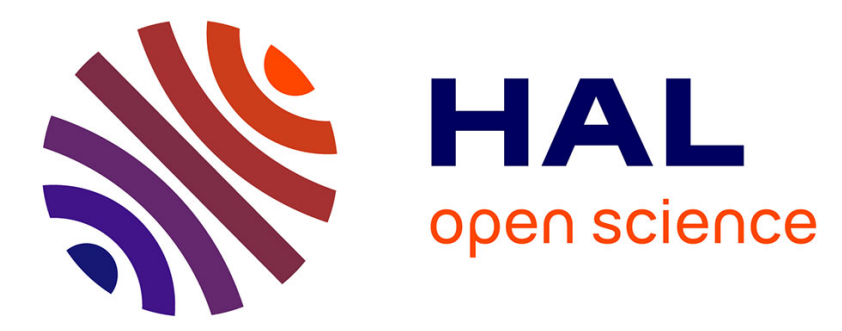

\title{
Microwave optical switches metal-semiconductor-metal Schottky based on GaAs
}

Sabah Benzeghda, Farida Hobar, Didier Decoster, Jean-Francois Lampin, A. Benzeghda

\section{- To cite this version:}

Sabah Benzeghda, Farida Hobar, Didier Decoster, Jean-Francois Lampin, A. Benzeghda. Microwave optical switches metal-semiconductor-metal Schottky based on GaAs. International Conference on Renewable Energies and Power Quality, ICREPQ'14, 2014, Córdoba, Spain. paper 534, 5 p., 10.24084/repqj12.534 . hal-00955226

\section{HAL Id: hal-00955226 \\ https://hal.science/hal-00955226}

Submitted on 10 Feb 2022

HAL is a multi-disciplinary open access archive for the deposit and dissemination of scientific research documents, whether they are published or not. The documents may come from teaching and research institutions in France or abroad, or from public or private research centers.
L'archive ouverte pluridisciplinaire HAL, est destinée au dépôt et à la diffusion de documents scientifiques de niveau recherche, publiés ou non, émanant des établissements d'enseignement et de recherche français ou étrangers, des laboratoires publics ou privés.

\section{다)(1) $(5$}

Distributed under a Creative Commons Attribution - NonCommercial| 4.0 International 


\title{
Microwave Optical Switches Metal-Semiconductor-Metal Schottky based on GaAs
}

\author{
S. Benzeghda ${ }^{1,2}$, F. Hobar ${ }^{1}$, Didier Decoster ${ }^{2}$ Jean-François Lampin ${ }^{2}$, A. Benzeghda \\ ${ }^{1}$ Laboratoire Microsystème et Instrumentation, Département d'Electronique, Université Mentouri Constantine, Route Ain El \\ Bey, 25000, Algérie. \\ ${ }^{2}$ Institute of Electronics, Microelectronics and Nanotechnology (IEMN), UMR CNRS 8520, Universite' des Sciences et \\ Technologies de Lille, BP 60069, 59652 Villeneuve d'Ascq Cedex, France \\ e-mail: benzeghdasabah@gmail.com
}

\begin{abstract}
Interdigitated metal-semiconductor-metal (MSM) photodetectors have received considerable attention for applications in microwave optical phoswitches. The impulse response of interdigitated metal-semiconductor- metal photoswich fabricated on GaAs non-intentional doped (NID) absorbing layer is investigated. The photodetector MSM is introduced in the microwave lines have active surfaces of $3 \times 3 \mu \mathrm{m} 2$ and electrode spacing of $0.2,0.3,0.5$ and $1 \mu \mathrm{m}$. . The photocurrent response was measured after excitation and we found that the screening of the dark electric field and charge accumulation exceedingly modify the drift conditions of the photogenerated electrons and holes in active region of the MSM photoswich.
\end{abstract}

\section{Key words}

Impulse response, MSM photodetector, space charge.

\section{Introduction}

High speed photodetectors are a key component of optoelectronic switching in coplanar transmission lines growth semiconductor material [1]. Planar metalsemiconductor-metal (MSM) photosensing structures with Schottky barriers have attracted much attention, inherent advantages include: lower capacitance, a large photosensitive surface, easy to integrate, low dark current and faster responses compared to PIN photodetectors [2], [3]. While mainly III-V semiconductor materials have been used for optoelectronic applications. This device is an interdigital comb $\left(\operatorname{Ti}\left(250 \mathrm{~A}^{\circ}\right) / \operatorname{Pt}\left(250 \mathrm{~A}^{\circ}\right) / \mathrm{Au}\left(4000 \mathrm{~A}^{\circ}\right)\right)$ leaving a free semiconductor surface between the two contacts which forms the active region in which light will be absorbed [4]. It located in the central strip of coplanar line, deposited over a non-intentional doped GaAs layer $(1014 \mathrm{~cm}-3)$, with thickness equal to $1 \mu \mathrm{m}$, epitaxially grown on a Semi-Insulating (S.I) substrate of $400 \mathrm{~mm}$ thick and crystal orientation $<1 \quad 0 \quad 0>$. The number of fingers $(\mathrm{N})$ and inter electrode spacing $(\mathrm{s})$ that is equal to the widths of fingers (1) and varies between $0.2,0.3,0.5$ and $1 \mu \mathrm{m}[5]$.
Our work has been concentrated on the response behavior of the MSM photoswitch, and how optical illumination and polarization will give appear to variety effect [6].

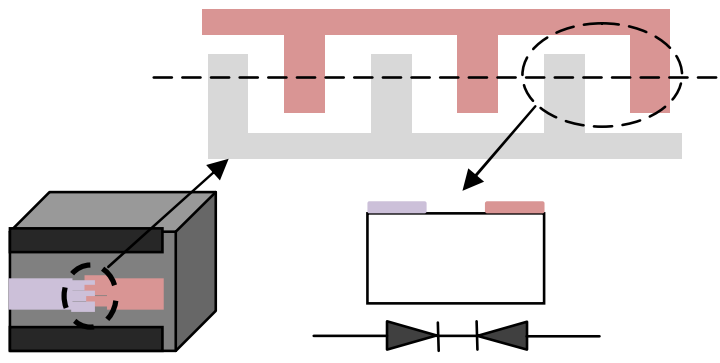

Fig. 1. Metal-Semiconducteor-Metal

\section{Results and discussion}

The time resolved photocurrent response was studied experimentally by exciting the photoswich with femtosecond laser with low-jitter pulse (Maï Taï HP of Spectra-physics), pulse width $100 \mathrm{fs,} \mathrm{wavelength} \mathrm{780nm,}$ repetition rate $80 \mathrm{MHz}$, Two microwave signal generators were used, the first for mounting up to $3 \mathrm{GHz}$ (Rhode and Schwartz SMA 100A) and the second to go up $20 \mathrm{GHz}$ (Anritsu MG3692A). The output signal was collected by tektronix DSA8200 oscilloscope. Depending on the characteristics of the laser pulse, including the wavelength and spectral width length, we arrive at a dispersion of 2 ps (fiber length of 1 meter, spectral width of the pulse at $0.8 \mu \mathrm{m}$ to $16 \mathrm{~nm}$ ), which is much higher to the original duration of the laser pulses (200 fs). Taking the value of the injection efficiency and the data of the chromatic dispersion giving pulse duration of about $2 \mathrm{ps}$, if we take $1,1 \mathrm{~mW}$ through lensed fiber output, a power peak is obtained $\sim 7$ Watts.

The test bench microwave coupled to a fiber illuminating the device from above. 


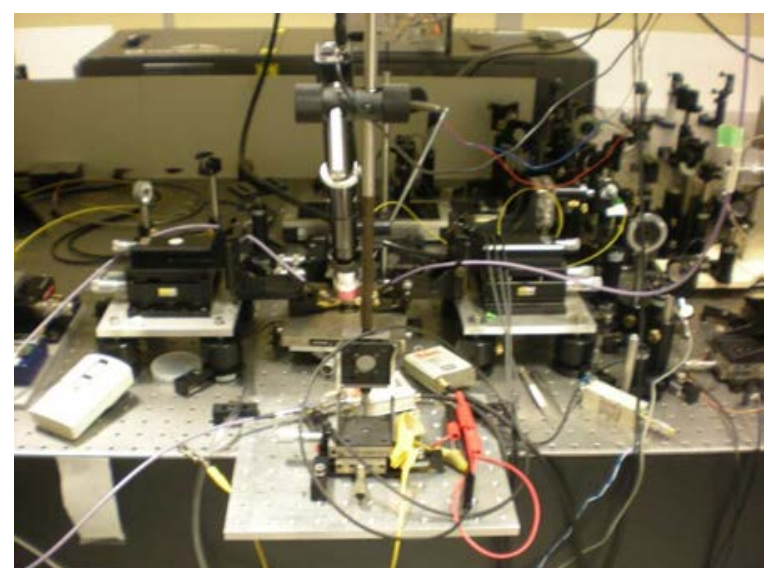

Fig. 2. The test bench microwave

Figure 3, shows the measured impulse response for MSM photoswitch with $3 \times 3 \mu \mathrm{m} 2$ active surface whose electrode spacing are $0.2 \mu \mathrm{m}, 0.3 \mu \mathrm{m}, 0.5 \mu \mathrm{m}$ and $1 \mu \mathrm{m}$ based on $\mathrm{GaAs}$ (N.I.D), as function of bias voltage.

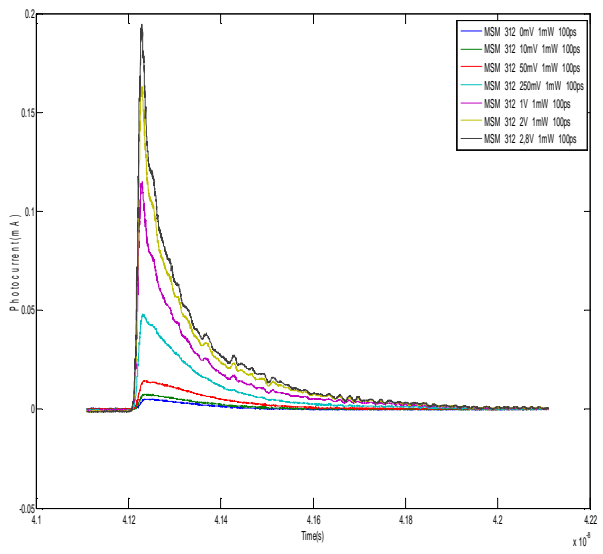

Fig. 3. Pulse response of GaAs MSM312 photoswitch at $\lambda=780 \mu \mathrm{m}$ with different bias voltages (Popt $=1 \mathrm{~mW}, \mathrm{~A}=3 \mathrm{x} 3 \mu \mathrm{m} 2$, $\mathrm{s}=\mathrm{l}=1 \mu \mathrm{m})$

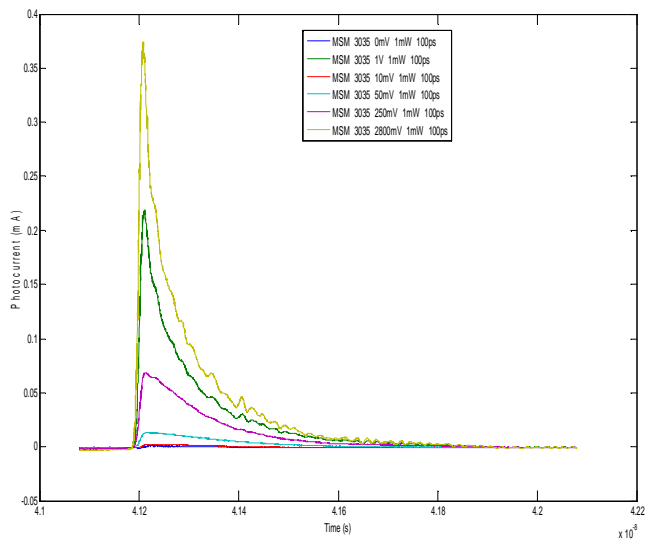

Fig. 4. Pulse response of GaAs MSM3035 photoswitch at $\lambda=780 \mu \mathrm{m}$ with different bias voltages (Popt $=1 \mathrm{~mW}, \mathrm{~A}=3 \times 3 \mu \mathrm{m} 2$, $\mathrm{s}=\mathrm{l}=1 \mu \mathrm{m})$

When a semiconductor material is illuminated by photons, this allows electron-hole pairs generated by the absorption of light and they start to distribute with field dependent drift velocities and gives rise to a photocurrent [6]. It may be noted that the pulse response of photoswitch at zero bias voltage is not negligible, the internal electric field is sufficient to collect the photogenerated carriers. The pulse shape is similar at different bias voltages; it has a faster rise time response, and faster initial sweep-out of the carriers, this fast leading part of the impulse response is chiefly due to the drift of electrons, followed by a slower long tail. The oscillations in the tail are most likely due to the impedance mismatch in the bond wires $[6,7]$.

To determine the lifetime of the carriers, we normalized the signal and we have shown in a logarithmic scale. Which of the following can we determine the lifetime of electrons by calculating the slope of the falling portion of the curve [8].

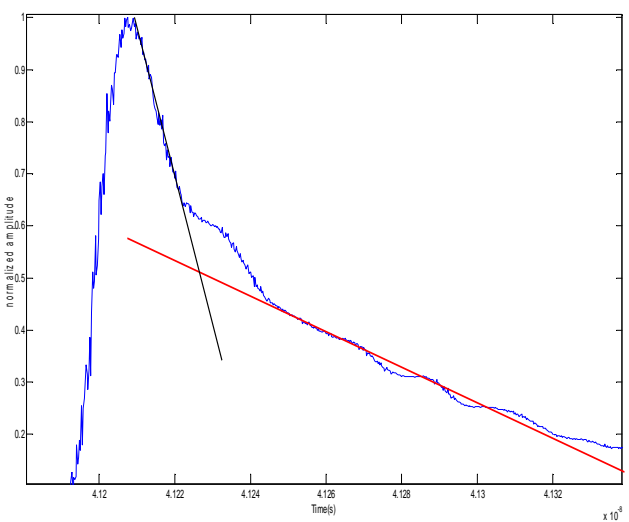

Fig. 5. Normalized amplitude of the temporal response of the MSM3035 at 2,8V to determine the lifetime of electrons and holes.

Table I. - Pulse response of GaAs MSM3035 photoswitch

\begin{tabular}{|l|l|l|l|}
\hline V[V] & $\begin{array}{c}\text { RISE } \\
\text { TIME[ps] }\end{array}$ & $\begin{array}{c}\text { FALL } \\
\text { TIME[ps }]\end{array}$ & FWHM[ps] \\
\hline 2,8 & 10 & 200 & 40 \\
\hline 1 & 10 & 220 & 50 \\
\hline 0,25 & 10 & 260 & 110 \\
\hline 0,05 & 14 & 330 & 160 \\
\hline
\end{tabular}

The rise and fall time (10\%-90\% of the maximum), and FWHM (Full width at half maximum) for the GaAs MSM3035 are indicated in Table 1.

Figure 4 shows the measured photocurrent of MSM with $0,3 \mu \mathrm{m}$ finger distance with different bias voltage $(0,0.05$, $0.25,1$ and $2.8 \mathrm{~V}$ ) and $1 \mathrm{~mW}$ optical power level as function of time delay. After excitation, the carriers start to move with field dependent drift velocities, for GaAs, vd increases linearly with electric field for fields up to about $3.2 \mathrm{kV} / \mathrm{cm}$. The finger distance is in submicron range it conducts to a full depletion region between electrodes, and this is result of the rapid extraction of electrons [8, 9], this leads to faster rise time of $10 \mathrm{ps}$, it is almost constant independent of voltage. The photogenerated carriers distribute in the semiconductor, they have a new velocity vectors. This fast rise time is flowed by fairly fast decay corresponding to the rapid collection of electrons and holes at contacts; this conducts to decrease of FWHM (Table I), subsequently to slower long tail which reflects 
the difference in drift velocities of electrons and holes [9, 10].

With small interelectrode distances, although with increasing bias voltage, this leads to high electrical field, and ensure velocity saturation, due to the initial opposite movement of electrons and holes cloud toward contacts [12], so the electric field is screened by the space charge. Near the anode, in the low field region electron-hole plasma is formed, this region contains more holes than electrons, where they move at much lower velocities [6, $10,12,13,14]$. When substrate is deeper, these carriers are collected at much lower speeds [11], it explained as follows: inside the space-charge region, a strong field accelerates electrons towards the bulk just beyond this region, a retarding filed sweeps the electrons toward the surface [15], this leads to increase fall time.

In addition, increasing of carriers' velocity with increasing field usually called 'Negative Differential Resistivity' (NDR) often is mentioned 'Gun effect' [16]. Gunn has discovered a new kind of current oscillations at microwave frequencies, in n-type GaAs, as the electric field increases, it leads to transfer of electrons from the high-mobility conduction band valley centered (low value of the wave vector $\mathrm{k}$ ) ( $\Gamma$ valley), to higher energy, low-mobility satellite valleys ( $\mathrm{L}$ and $\mathrm{X}$ ), therefore, an increase in the electron effective mass and an increase in the density of electron states from the low-energy valley to the highenergy valley leads decrease in velocity $[16,17,18]$, figure 5.

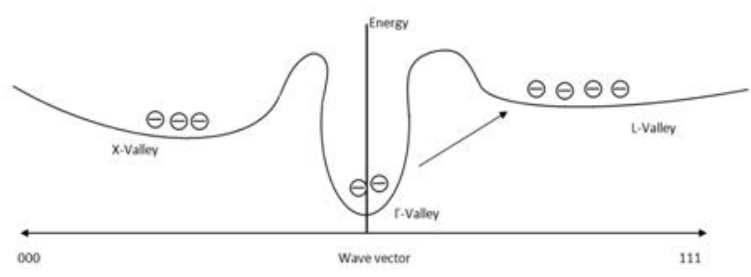

Fig. 6. Gunn Effect

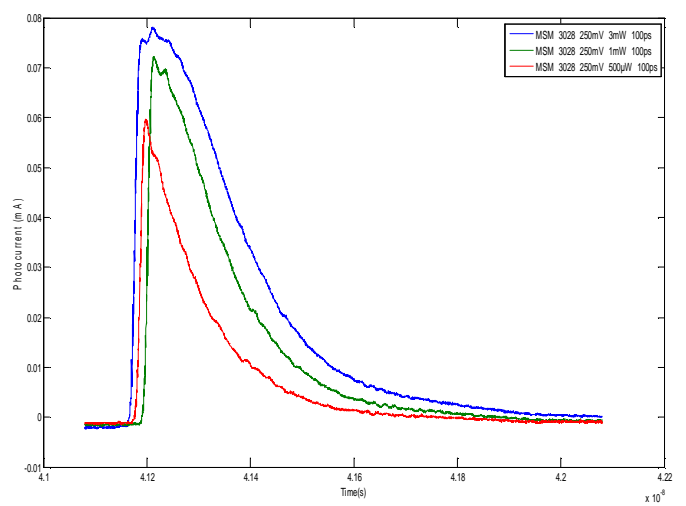

Fig. 7. Pulse response of GaAs MSM3028 photoswitch at $\lambda=780 \mathrm{~nm}$ with different optical power levels $(\mathrm{V}=250 \mathrm{~mW}$, $\left.\mathrm{A}=3 \times 3 \mu \mathrm{m}^{2}, \mathrm{~s}=\mathrm{l}=0,2 \mu \mathrm{m}\right)$

Figure 7, presents the pulse response of MSM3028 photoswitch as function of incident optical power.
The rise and fall time, FWHM are shown in table:

Table II. - Pulse response of GaAs MSM3035 photoswitch.

\begin{tabular}{|l|l|l|l|}
\hline $\mathrm{P}_{\text {opt }}(\mathrm{mW})$ & $\begin{array}{l}\text { RISE TIME } \\
{[\mathrm{ps}]}\end{array}$ & $\begin{array}{l}\text { FALL } \\
\text { TIME }[\mathrm{ps}]\end{array}$ & FWHM[ps] \\
\hline 3 & 10 & 340 & 198 \\
\hline 1 & 14,8 & 280 & 140 \\
\hline 0,5 & 15 & 240 & 90 \\
\hline
\end{tabular}

The increase of FWHM and fall time of pulse response with increasing optical power is explained as follows. The pulse energy is high enough to cause accumulation in the active region, screening of internal electric field, and formed an electron hole plasma near the anode, this region behave like virtual anode because a lot of holes are still staying in this region $[6,13]$.

The transient current response is limited by another factor, the trapping at the surface states of semiconductor states carriers create surface charge layer, [15, 19], also, at active layer metal-semiconductor interface and/or at deep layer defects in band gab of the material can trap photgenerated carriers $[10,12,13,20,21,22]$.

We can neglect the screening of the internal electric field to have no effect on the MSM photoswitch response if the space charges are much less than the total charge accumulated at the contacts $[13,22,23]$. If each photon creates one electron-hole pair, the total number of the photogenerated carriers with total area L2 $[6,13]$ :

$\mathrm{N}=\frac{\mathrm{E} \lambda \mathrm{s}}{\mathrm{hc}(\mathrm{s}+\mathrm{l})}(1-\mathrm{r})[1-\exp (-\alpha \mathrm{d})](1)$

Where $\mathrm{d}$ is the thickness of the active layer, $\alpha$ is the light absorption coefficient, $r$ is the reflection coefficient, $\lambda$ is the wavelength, $\mathrm{c}$ is velocity of light in a vacuum, $\mathrm{h}$ is the Planck constant, E is the optical pulse of energy. The condition can be expressed by [23]:

$$
\mathrm{E}<\frac{\varepsilon_{0}\left(\varepsilon_{\mathrm{s}}+1\right) \mathrm{L}^{2} \mathrm{~V}(\mathrm{l}+\mathrm{s}) \mathrm{hc}}{4 \lambda \mathrm{qs} \mathrm{s}^{2}(1-\mathrm{r})[1-\exp (-\alpha \mathrm{d})]}
$$

Where $\mathrm{q}$ is the elementary charge, $\mathrm{V}$ is the external bias voltage.

We finally obtain [13]:

$$
\mathrm{N}_{\mathrm{ph}} \ll \frac{\mathrm{CV}}{\mathrm{qL}}
$$

Where, $\mathrm{C}$ is the dark capacitance:

$$
\mathrm{C}=\frac{\varepsilon_{0}\left(\varepsilon_{\mathrm{s}}+1\right) \mathrm{L}^{2}}{4 \mathrm{~s}}
$$

The interdigited MSM photoswitch geometry can be optimized, in order to achieve a fast pulse response, the width of interelectrode gap [23]:

$$
s=\frac{M}{s+1}\left[6.5 \eta^{2}+1.08 \eta+2.37\right]
$$


Where:

$$
\begin{gathered}
\eta=\frac{\mathrm{l}}{\mathrm{l}+\mathrm{s}}(6) \\
\mathrm{M}=4.4 \mathrm{RL}^{2} \frac{\mathrm{v}}{\chi}\left(\varepsilon_{\mathrm{s}}+1\right) 10^{-12}
\end{gathered}
$$

$\chi$ is carrier driftdistance corrective coefficient

$\mathrm{V}$ is velocity of ambipolar carrier drift

By solving this equation, we found the optimum interelectrode gap:

$$
\mathrm{S}_{\mathrm{opt}}=\frac{\mathrm{L}}{2} \sqrt{2.2 \mathrm{RV} \mathrm{V}_{\mathrm{sat}} \varepsilon_{0}\left(\varepsilon_{\mathrm{s}}+1\right)}(8)
$$

Vsat is the saturation velocity, for GaAs MSM $(\sim 105 \mathrm{~m} / \mathrm{s})$, and $\mathrm{R}=50 \Omega[6,23]$ :

$$
\mathrm{s}_{\mathrm{opt}} \approx 0.02 \mathrm{~L}(9)
$$

\section{Conclusion}

The impulse response of GaAs MSM photoswitch for different bias voltage and optical power and gap between fingers, for $\lambda=780 \mathrm{~nm}$ was studied experimentally. The pulse shape of the impulse response is similar, it achieves maximum after fast rise time due to fast electron drift velocity, flowed by fairly fast decay corresponding to the fast escape of electrons and holes to the interdigitated contacts, small Schottky contact spacing permitting rapid carrier extraction after photoexcitation, however, it followed by long tail. High electric field reaches a threshold level, the mobility of electrons decrease as the electric field is increased, due to the screening of internal field; thereby producing negative resistance (NDR). The trapping effect is another feasible way to reduce the carrier transit time. It is advantageous to use thin active layers to reduce the transient response.

As perspective, and for improvement this work, we'll modeled a GaN-based MSM to use it like photovoltaic ultraviolet detector.

\section{References}

[1]. W.C. von Wendorff, M. Welters, D. Jäger, Optoelectronic switching in travelling-wave MSM photodetectors using photon energies below bandgap, Electronics Letters, vol.26, no.22, pp. 1874-1875, (1990).

[2]. David Crouse, Mark Arend, Jianping Zou, Pavan Keshavareddy Numerical modeling of electromagnetic resonance enhanced silicon metal-semiconductor-metal photodetectors, Optics Express, Vol. 14, Issue 6, pp. 2047-2061 (2006).

[3]. Andreas P. Glinz, Charles B. Morrison, and Zheng Zhu, Modeling of wide-area thin film metalsemiconductor-metal photodetectors for LIDAR applications, SPIE Proc. SPIE 3283, Physics and Simulation of Optoelectronic Devices VI, 960; doi:10.1117/12.316651; (1998).

[4]. Didier Decoster Joseph Harari, Optoelectronic Sensors, second ed. (Wiley, 2001, pp. 10).
[5]. A. D. Zebentout, Z. Bensaad, M. Zegaoui, A. Aissat, D. Decoster, Effect of Dimensional Parameters on the Current of MSM Photodetector, Microelectronics Journal, Volume 42, Issue 8, August 2011, pp. 10061009.

[6]. S.V.Averine, R.Sachot Transit-time considerations in metal-semiconductor-metal photodiode under high illumination conditions, Solid-State Electronics, vol. 44, N 9, pp.1627-1634, (2000).

[7]. J. Rosenzweig, C. Moglestue, A. Axmann, Jo. Schneider, and A. Hulsmann, Characterization of picosecond GaAs metal-semiconductor-metal photodetectors, SPIE Vol. 1362 Physical Concepts of Materials for Novel Optoelectronic Device Applications , pp 168, 178, (1990).

[8]. Siham BADI, Interfaces optoélectroniques ultrarapides pour l'électronique supraconductrice à quantum de flux magnétique, Ph.D. dissertation, Savoie University, pp 157, (2009).

[9]. Nanoscale Tera-Hertz Metal-Semiconductor-Metal Photodetectors Stephen Y. Chou, Mark Y. Liu, IEEE Journal of Quantum Electronics (ISSN 0018-9297), vol. 28, no. 10, p. 2358-2368, (1992).

[10].M. Lambsdorff, M. Klingenstein, J. Kuhl, C. Moglestue, J. Rosenzweig, Subpicosecond characterization of carrier transport in GaAsmetal semiconductormetal photodiodes, Appl. Phys. Lett. 58, doi: 10.1063/1.105208, pp 1410-1412, (1991).

[11].Honkanen, Katri, Fabrication and modelling of SOI and GaAs MSM photodetectors and a GaAs-based integrated photoreceiver, Phd, Department of Electrical and Communications Engineering (Sähköja tietoliikennetekniikan osasto), 2001

[12].M. Klingenstein, J. Kuhl, J. Rosenzweig, C. Moglestue, A. Hülsmann, Time resolved photocurrent response of metal semiconductor metal photodetectors to doublepulse excitation, Appl. Phys. Lett. 63, doi: 10.1063/1.110332, 2780-2782, (1993).

[13].Detlef Kuhl, Frank Hieronymi, E. Holger Bottcher, Torsten, Influence of Space Charges on the Impulse Response of InGaAs Metal-Semiconductor-Metal Photodetectors, Journal of Lightwave. Technology, Vol. 10, No. 6, 753-759, (1992).

[14].M. Klingenstein, J. Khul, R. Notzel, K. Ploog, J. Rosenzweig, C. Moglestue, A. Hulsmann, J . Schneider, and K. Kohler, Ultrafast

[15].metal-semiconductor-metal-photodiodes fabricated on low-temperature GaAs, Appl. Phys. Lett., vol. 60, pp. 627-629, (1992).

[16].Xia Zhao, Marc Currie, Adriano Cola, Fabio Quaranta, Eric Gallo, Jonathan E. Spanier, and Bahram Nabet, Time Response of Two-Dimensional Gas-Based Vertical Field Metal-SemiconductorMetal Photodetectors, IEEE transactions on electron devices, vol. 55, No. 7, 1762-1770, (2008).

[17].Lawrence Eric Kingsley, A study of picosecond, high-voltage photoconductive switching using electrooptic diagnostics and computer-aided analysis, Requirements for the Degree of Doctor of philosophy, University of Rochester, New York (1991). 
[18].J. B. Gunn , Instabilities of Current in III-V Semiconductors, IBM Journal of Research and Development, Volume:8 Issue:2, 141-159, (1962).

[19].W.Shockley, Negative Resistance Arising from Transit Time in Semiconductor Diodes, Bell Syst. Tech. J, vol. 33, pp. 799-826, (1954).

[20].F. Hobar, Etude et realization de structure photoresistances interdigitées pour la detection optique, $\mathrm{PhD}$, Paris Sud (Orsay), (1984).

[21].J. P. Salvestrini ; A. Ahaitouf ; H. Srour ; S. Gautier ; T. Moudakir ; B. Assouar ;A. Ougazzaden, Tuning of internal gain, dark current and cutoff wavelength of UV photodetectors using quasi-alloy of BGaN-GaN and BGaN-AlN superlattices, Proc. SPIE 8268, Quantum Sensing and Nanophotonic Devices IX, 82682S (2012); doi:10.1117/12.914800, Invited paper.

[22].J. F. Holzman, F. E. Vermeulen, and A. Y. Elezzabi, Recombination-independent photogeneration of ultrashort electrical pulses, Applied physics letters volume 76, No , pp 134-136, (2000).

[23]. Averine S. V. and Kuznetzov P. I , Effect of optical excitation level on the msm-detector high-speed response, Ultrawideband and Ultrashort Impulse Signals, Sevastopol, Ukraine pp. 138-140, (2008).

[24].Stanislav Averine, Yuen Chuen Chan, Yee Loy Lam, Geometry optimization of interdigitated MetalSemiconductor-Metal photodiode structures, Design, Modeling, and Simulation in Microelectronics, Bernard Courtois, Serge N. Demidenko, L. Y. Lau, Editors, Proceedings of SPIE Vol. 4228, pp 323-329, (2000). 